\title{
Cone Beam Computed Tomographic Findings of Double Osteomas with Maxillary Sinusitis
}

\author{
Seo-Young An, ${ }^{1}$ Suk-Ja Yoon, ${ }^{2}$ Byung-Cheol Kang, ${ }^{2}$ Ok-Jun Kim, ${ }^{3}$ Min-Suk Kook, ${ }^{4}$ and Jae-Seo Lee ${ }^{2,}$ \\ ${ }^{1}$ Department of Oral and Maxillofacial Radiology, School of Dentistry, Kyungpook National University, Daegu, Republic of Korea \\ ${ }^{2}$ Department of Oral and Maxillofacial Radiology, School of Dentistry, Dental Science Research Institute, Chonnam National University, Gwangju, Republic of Korea \\ ${ }^{3}$ Departement of Oral Pathology, School of Dentistry, Dental Science Research Institute, Chonnam National University, Gwangju, Republic of Korea \\ ${ }^{4}$ Department of Oral and Maxillofacial Surgery, School of Dentistry, Dental Science Research Institute, Chonnam National University, Gwangju, Republic of Korea \\ "Corresponding author: Jae-Seo Lee, Department of Oral and Maxillofacial Radiology, School of Dentistry, Dental Science Research Institute, Chonnam National University, \\ Gwangju, Republic of Korea. E-mail: jsyi16@jnu.ac.kr
}

Received 2016 September 05; Revised 2017 February 20; Accepted 2017 March 08.

\begin{abstract}
An osteoma may originate from cartilage or embryonal periosteum. It may occur externally or within the paranasal sinuses. In most cases, a paranasal osteoma is a solitary lesion and is located in a single sinus. A double osteoma with maxillary sinusitis is rare. A 54year-old woman was referred for evaluation and treatment of a right maxillary sinus bony lesion. She complained of headache and foul smell after sneezing since 1 month ago. Panoramic radiography revealed two radiopaque masses in the right maxillary sinus. Cone beam computerized tomography images revealed radiopacities with partially corticated borders attached to the medial wall of the right maxillary sinus, near-complete radiopacification of the right maxillary sinus, and peripheral bony thickening due to chronic sinusitis. On histopathologic examination, the removed radiopaque masses were diagnosed as osteomas.
\end{abstract}

Keywords: Osteoma, Maxillary Sinusitis, Cone Beam Computed Tomography

\section{Introduction}

Osteomas are slow-growing, osteogenic benign tumors that arise from proliferation of either cancellous or compact bone (1).

The most common location is the mandible, followed by the paranasal sinuses. Osteomas frequently occur in the frontal sinus, followed by the ethmoid, maxillary, and rarely sphenoid sinuses $(2,3)$. Most osteomas are asymptomatic and are detected incidentally on radiographic examination for another purpose (2); however, depending on their location and size, they lead to headaches, proptosis, diplopia, and dizziness (4-6).

Most osteomas in the craniofacial bone occur as a solitary lesion (7). Detection and correct interpretation of bony lesions of the maxillary sinus is important for deciding the proper treatment and improving the prognosis. Cone beam computed tomography (CBCT) has been found superior to the panoramic radiograph for detection of bony lesions of the maxillary sinuses.

We report a rare case of double osteoma with maxillary sinusitis in a patient without Gardner's syndrome and describe the radiographic appearance of osteomas and maxillary sinusitis on cone beam computed tomography (CBCT).

\section{Case Presentation}

A 54-year-old woman without significant medical history presented to the department of oral and maxillofacial surgery of Chonnam national university hospital. She was referred for evaluation of bony lesions of the right maxillary sinus. She complained of headache and foul smell after sneezing since 1 month ago.

A panoramic radiograph revealed two radiopaque masses in the right maxillary sinus (Figure 1).

Coronal CBCT images revealed two radiopacities attached to the medial wall of the right maxillary sinus. The radiopacities were seen as heterogeneous matrix with a partial corticated border, and they were seen to arise from the medial wall of the right maxillary sinus extending distally, filling one third of the right maxillary sinus. Axial CBCT images revealed that the first osteoma was shaped as a disc with curvature, and the second was round-shaped. The lengths of the osteomas on the axial image were $7 \times$ $15 \mathrm{~mm}$ and $8 \times 15 \mathrm{~mm}$, respectively. The right maxillary sinus showed near-complete radiopacification and peripheral bony thickening due to chronic sinusitis (Figure 2). The differential diagnosis of the lesions included antrolith, osteoma, complex odontoma, and calcification in chronic maxillary sinusitis.

The radiopaque masses were surgically excised via a Caldwell-Luc procedure (Figure 3). 


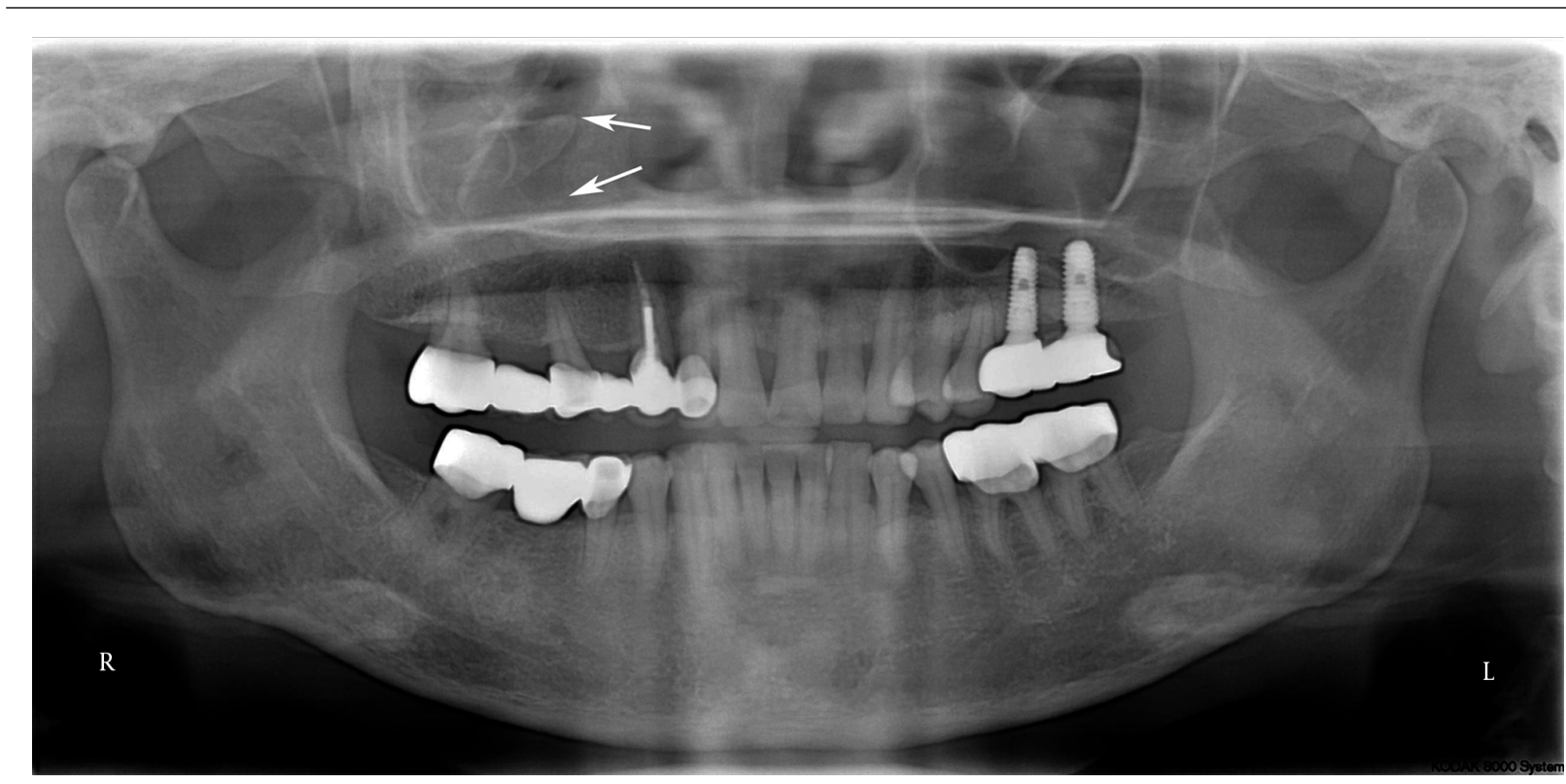

Figure 1. A 54-year-old woman with headache and foul smell after sneezing since 1 month ago. She was referred for evaluation of a bony lesion in the right maxillary sinus. Panoramic radiograph reveals two radiopaque masses occupying the right maxillary sinus.

Histopathologic examination of the removed radiopaque masses revealed mature trabecular bone with hematopoietic elements, fatty infiltration and fibrous tissue surrounded by a demarcated cortical bone. The diagnosis was mixed type osteoma (Figure 4).

After 1 year of follow-up, the patient was free of symptoms and had no signs of recurrence.

\section{Discussion}

The etiology of osteoma is not clearly understood, and embryologic, traumatic, and infectious theories are proposed $(8,9)$. Osteoma may arise as a result of infection stimulating osteoblasts, which in turn may become secondarily calcified (10). Our patient had chronic infection symptoms related to maxillary sinusitis. Long-standing chronic maxillary sinusitis in pediatric patients results in a decrease in the volume of the maxillary sinuses and an increase in bony thickness of paranasal sinuses (11). In this case, bony changes due to chronic maxillary sinusitis were seen. CBCT revealed sclerotic bony thickening and an irregular border of the inner wall of the right maxillary sinus, which indicated periosteal new bone formation due to sinusitis (Figure 2). Two radiopacities with a partially corticated border in the right maxillary sinus were also detected.

The differential diagnosis of antral radiopaque lesions in this case included antrolith, osteoma, complex odontoma, and calcification in chronic maxillary sinusitis.
Retrospective studies of antroliths showed that most cases were related to sinus infection. Antrolith may occur around a nidus that continues to grow by deposition of mineral salts (12). It could have a pitted or laminated surface. In this study, the removed specimens had a smooth surface (Figure 3), which indicated a possible osteoma, complex odontoma, or intrasinus calcification with fungal sinusitis.

In a previoius study (13), the prevalence of intrasinus calcifications on CT scans in patients with sinonasal fungus ball has been reported as $67.2 \%$ (116 cases). The calcifications were located mostly in the center of the maxillary sinus (85.9\%), followed by near the sinus wall (7.7\%). Nodular (53.8\%), linear (20.5\%), mixed (11.5\%), round (10.3\%), and fine punctate $(3.8 \%$ ) calcifications are seen with fungal sinusitis. A round-shaped, intrasinus calcification with maxillary sinusitis may be similar in appearance to an osteoma, but dystrophic calcification in sinusitis is separated from the sinus wall.

In this case, heterogeneous radiopacities with partially corticated shell were attached to the medial wall of the right maxillary sinus on coronal CBCT images, which was helpful in the differential diagnosis from an intrasinus calcification due to maxillary sinusitis.

Histologically, osteoma has three variants: compact osteoma (dense bone with minimal marrow space), cancellous osteoma (bony trabeculae and fibrofatty marrow), and mixed type osteoma $(1,2,14)$. The present case was of a 

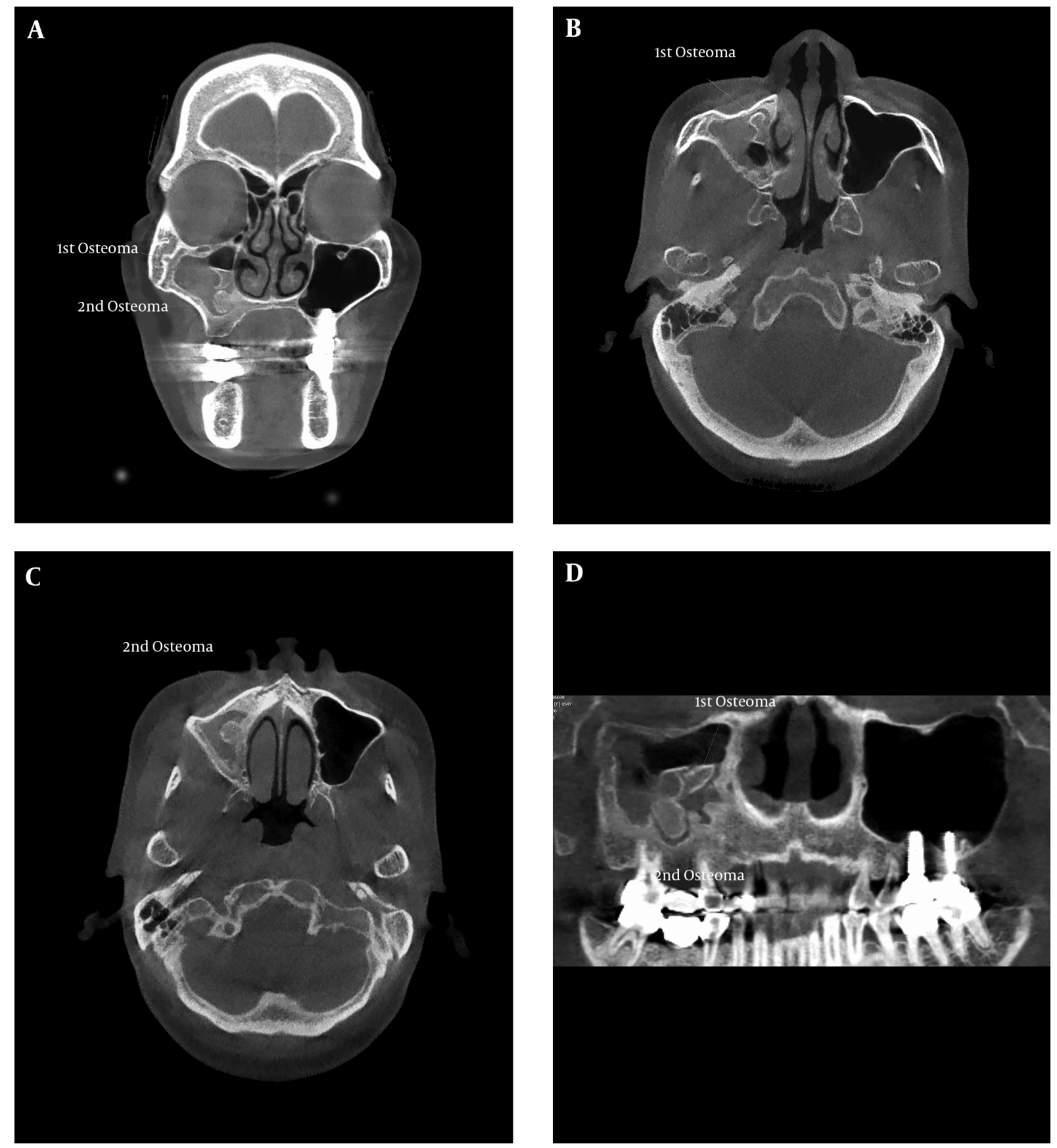

Figure 2. Cone beam computed tomography (CBCT). A, Coronal view; B and C, Axial view; and D, Reconstructed panoramic image reveals two radiopacities with partially corticated borders attached to the medial wall of the right maxillary sinus. The right maxillary sinus shows near-complete radiopacification and peripheral bone thickening due to chronic sinusitis.

mixed type osteoma.

Symptoms of paranasal sinus osteoma are variable, and are associated with the size, location, and growth rate of the tumor. Symptomatic osteomas and large (extend- ing to more than $50 \%$ of the sinus) or growing osteomas should be surgically removed (15). However, management of asymptomatic osteoma is controversial (10).

The management options for paranasal sinus osteo- 


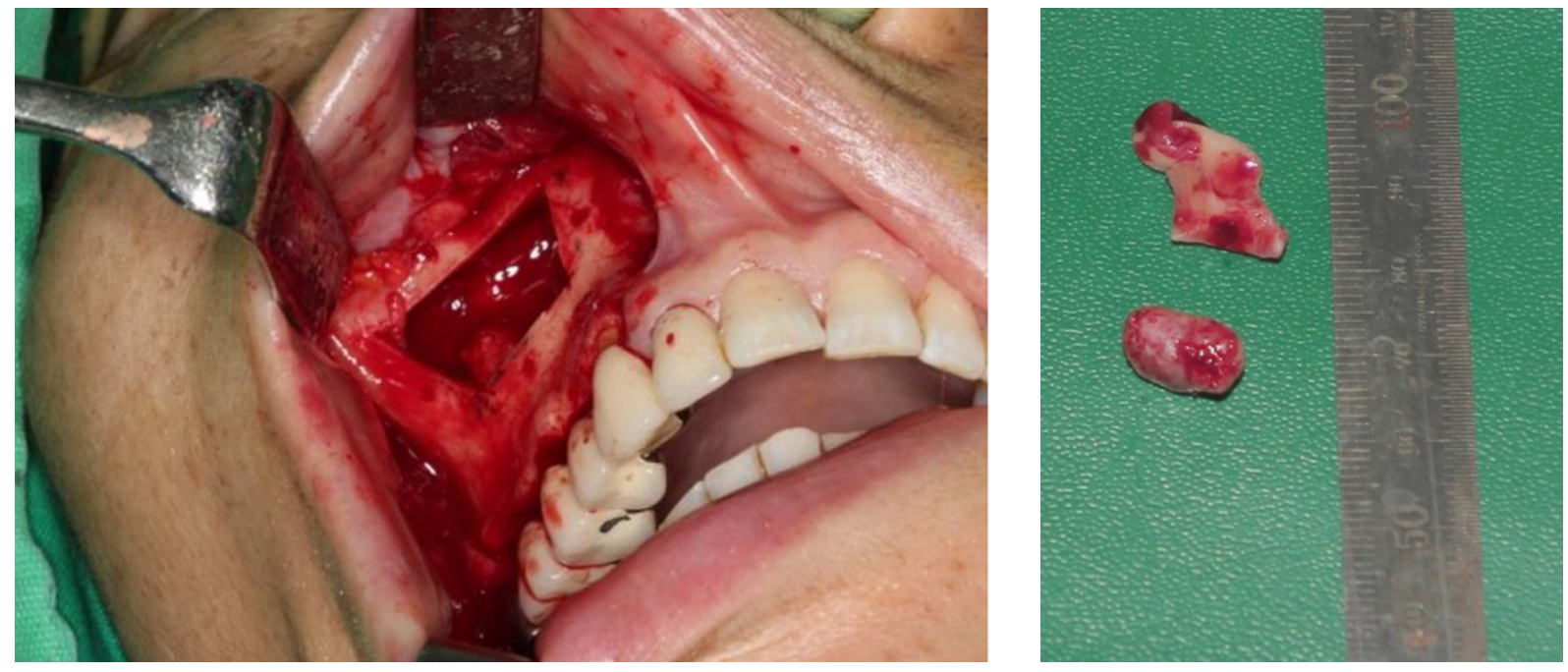

Figure 3. The radiopaque masses were surgically excised via a Caldwell-Luc procedure.

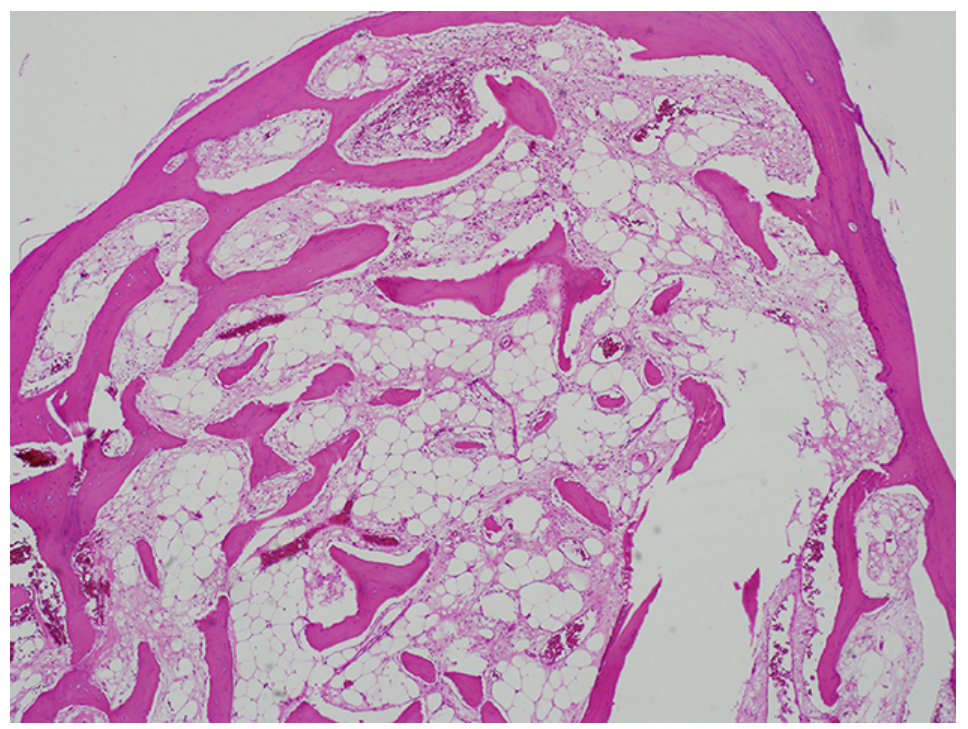

Figure 4. Histopathologic examination revealed mature trabecular bone with hematopoietic elements, fatty infiltration and fibrous tissue is surrounded by a demarcated cortical bone.

mas include surgical endoscopic surgery, an external approach, or a combined approach using both procedures. The type of surgical procedure is determined by lesion size and location (16). Recurrence of osteomas after surgical removal is rare, but incomplete resection of an osteoma could lead to regrowth (17). There are no guidelines on postoperative follow-up. However, periodic radiological evaluation is recommended after incomplete resection (18).

Other than in Gardner's syndrome, which is character- ized by intestinal polyposis, multiple osteomas, cutaneous fibromas, epidermal cysts, and impacted supernumerary teeth, osteomas of the craniofacial bones are solitary lesions $(7,19)$.

Buyuklu et al (2). reported that only two patients had multiple osteoma in 17,154 paranasal sinus CT scans of 14,137 patients. However, the lesions were not found in the maxillary sinus but in frontal and ethmoidal sinuses (2).

To the best of our knowledge, double osteoma of a single maxillary sinus is very rare. Our patient did not 
have Gardner's syndrome but double osteoma coexisting with sinusitis was detected. Osteoma should be considered in the differential diagnosis of a radiopaque paranasal lesion. CBCT images may be helpful in diagnosing osteoma and peripheral bone changes due to maxillary sinusitis not clearly seen on panoramic radiograph.

\section{Footnotes}

Ethics Statement / Confirmation of Patient Permission: Due to the nature of case report of this study, it was granted an exemption in writing by the IRB of Chonnam national university dental hospital, and informed consent was obtained from the patient, and identifying details were omitted in this study.

Financial Disclosure: The authors declare that there are no competing interests.

\section{References}

1. Sayan NB, Ucok C, Karasu HA, Gunhan O. Peripheral osteoma of the oral and maxillofacial region: a study of 35 new cases.J Oral Maxillofac Surg. 2002;60(11):1299-301. [PubMed: 12420263].

2. Buyuklu F, Akdogan MV, Ozer C, Cakmak O. Growth charac teristics and clinical manifestations of the paranasal sinus osteomas. Otolaryngol Head Neck Surg. 2011;145(2):319-23. doi: 10.1177/0194599811403380. [PubMed: 21493269].

3. Zouloumis L, Lazaridis N, Maria P, Epivatianos A. Osteoma of the ethmoidal sinus: a rare case of recurrence. $\mathrm{Br} J$ Oral Maxillofac Surg. 2005;43(6):520-2. doi: 10.1016/j.bjoms.2005.01.014. [PubMed: 15908072].

4. Summers LE, Mascott CR, Tompkins JR, Richardson DE. Frontal sinus osteoma associated with cerebral abscess formation: a case report Surg Neurol. 2001;55(4):235-9. [PubMed: 11358601].

5. Kim AW, Foster JA, Papay FA, Wright KW. Orbital extension of a frontal sinus osteoma in a thirteen-year-old girl. J AAPOS. 2000;4(2):122-4 [PubMed: 10773813].
6. Viswanatha B. Maxillary sinus osteoma: two cases and review of the literature. Acta Otorhinolaryngol Ital. 2012;32(3):202-5. [PubMed: 22767988].

7. Kaplan I, Nicolaou Z, Hatuel D, Calderon S. Solitary central osteoma of the jaws: a diagnostic dilemma. Oral Surg Oral Med Oral Pathol Oral Radiol Endod. 2008;106(3):22-9. doi:10.1016/j.tripleo.2008.04.013. [PubMed: 18602294].

8. Eller R, Sillers M. Common fibro-osseous lesions of the paranasal sinuses. Otolaryngol Clin North Am. 2006;39(3):585-600. doi: 10.1016/j.otc.2006.01.013. [PubMed:16757233] x.

9. Cutilli BJ, Quinn PD. Traumatically induced peripheral osteoma. Report of a case. Oral Surg Oral Med Oral Pathol. 1992;73(6):667-9. [PubMed: 1437033].

10. Georgalas C, Goudakos J, Fokkens WJ. Osteoma of the skull base and sinuses. Otolaryngol Clin North Am. 2011;44(4):875-90. doi: 10.1016/j.otc.2011.06.008. [PubMed: 21819877] vii.

11. Kim HY, Kim MB, Dhong HJ, Jung YG, Min JY, Chung SK, et al. Changes of maxillary sinus volume and bony thickness of the paranasal sinuses in longstanding pediatric chronic rhinosinusitis. Int J Pediatr Otorhinolaryngol. 2008;72(1):103-8. doi: 10.1016/j.ijporl.2007.09.018. [PubMed: 18022702].

12. Nass Duce M, Talas DU, Ozer C, Yildiz A, Apaydin FD, Ozgur A. Antrolithiasis: a retrospective study. J Laryngol Otol. 2003;117(8):63740. doi: 10.1258/002221503768199997. [PubMed: 12956920].

13. Seo YJ, Kim J, Kim K, Lee JG, Kim CH, Yoon JH. Radiologic characteristics of sinonasal fungus ball: an analysis of 119 cases. Acta Radiol. 2011;52(7):790-5. doi: 10.1258/ar.2011.110021. [PubMed: 21525111].

14. Rajayogeswaran V, Eveson JW. Endosteal (central) osteoma of the maxilla. Br Dent J. 1981;150(6):162-3. [PubMed: 6938210].

15. Koivunen P, Lopponen H, Fors AP, Jokinen K. The growth rate of osteomas of the paranasal sinuses. Clin Otolaryngol Allied Sci. 1997;22(2):1114. [PubMed: 9160920].

16. Celenk F, Baysal E, Karata ZA, Durucu C, Mumbuc S, Kanlikama M. Paranasal sinus osteomas. J Craniofac Surg. 2012;23(5):433-7. doi: 10.1097/SCS.0b013e31825e4b5b. [PubMed: 22976695].

17. Atallah N, Jay MM. Osteomas of the paranasal sinuses. J Laryngol Otol. 1981;95(3):291-304. [PubMed: 7462794].

18. Edmond M, Clifton N, Khalil H. A large atypical osteoma of the maxillary sinus: a report of a case and management challenges. Eur Arch Otorhinolaryngol. 2011;268(2):315-8. doi: 10.1007/s00405-010-1447-0. [PubMed: 21132319].

19. Payne M, Anderson JA, Cook J. Gardner's syndrome - a case report. Br Dent J. 2002;193(7):383-4. doi: 10.1038/sj.bdj.4801571. [PubMed: 12420008]. 